\title{
Determination of the own forms of vibration of the span of beam bridges on elastic supporting parts
}

\author{
Muhtar Apsemetov, Nurzhan Madanbekov, and Tologon Muktarov \\ Kyrgyz State University of Construction, Transportation and Architecture, Bishkek, Kyrgyzstan
}

\begin{abstract}
The authors consider the determination of the eigenforms of a beam on elastic support parts. Elastic support parts made of rubber and laminated metal plates find a wide use for seismic isolation of bridges in earthquake-resistant construction. Determination of eigenforms of structures is the main stage when designing the buildings and structures for resisting the seismic impacts. The span structure of girder bridges is considered as a system of uniformly distributed load, the free vibrations of which are described by a homogeneous fourth-order partial differential equation. By solving the differential equation, formulas for determining the eigenforms of a beam on elastic support parts were obtained. The reliability of the obtained formulas is confirmed with the substitution of other boundary conditions of the beam. The formulas obtained are considered as a general case, and from them the special cases for different ways of fixing of beams can be obtained.
\end{abstract}

\section{Introduction}

Buildings and structures in seismic areas are designed and constructed considering seismic impacts with a certain intensity depending on the scale of construction sites. The bridge spans are also designed for vertical moving loads.

Determination of the natural vibration modes of beams is the most important task when calculating spans for dynamic loads. Rubber bearings are widely used in the bridge construction [1]. When vertical and horizontal vibrations of the span are combined, the elastic support parts change shape and the natural vibration modes of beam, reducing the effects of dynamic loads on spans $[2,3,4,5,6]$.

The rubber bearing parts are widely used in bridge construction and in this work the vertical transverse free vibrations along the $\boldsymbol{y}$-axis of the span structure of a beam bridge on elastic supports are considered.

Horizontal transverse vibrations along the $z$-axis is considered in the same way by replacing $\boldsymbol{y}$ with $\boldsymbol{z}$.

\section{Research methods}

To determine the natural modes of vibrations of the beam, the natural vibrations of the beam are considered, which is described by a fourth-order partial differential equation. 
The method of structural mechanics, special part of construction dynamics, was applied to obtain the deflection, the angle of rotation, the shear force, and the moment in the sections of the beam with free vibration.

By placing the boundary conditions of the beam on the elastic support parts into these expressions, the natural modes of vibration are determined.

Simplification of the cumbersome formulas associated with the Krylov functions were carried out by methods of mathematical analysis.

In the analysis of the obtained formulas for the natural vibration modes on elastic support parts and in the transition from the general case to the special case, the function limit was used.

\section{Results and Discussion}

The bridge framework is considered as a beam fixed on both ends. It is assumed that each bridge spans are independent to each other. We will consider a beam with elastic supports (Fig. 1). Normal vibrations of a beam with a uniformly distributed mass without attenuation are described by a fourth-order partial differential equation [7 - 12].

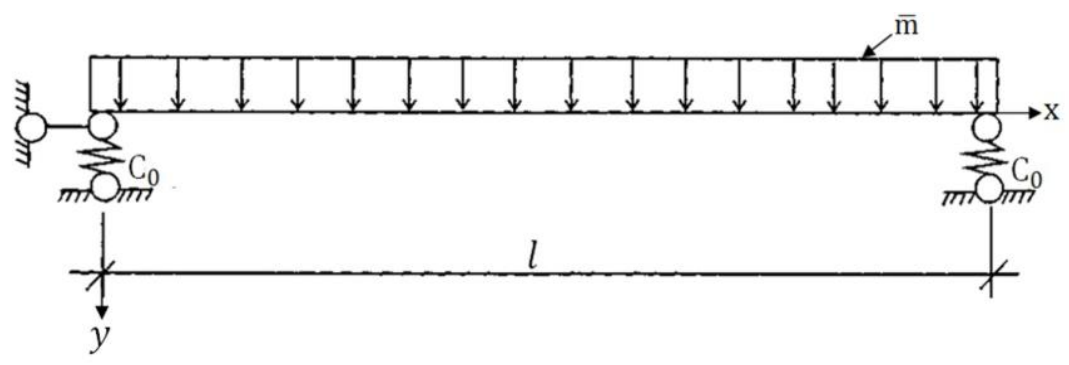

Fig. 1. Design of a beam on elastic supports

$$
E J \frac{\partial^{4} y}{\partial x^{4}}+\frac{\bar{m} \partial^{2} y}{\partial x^{2}}=0
$$

where $E J$ is the beam's stiffness, $\bar{m}$ is the mass of beam's length unit.

The solution (1) can be represented in Fourier form $(x, t)=y(x) \times \Phi(t)$, which leads to two ordinary differential equations

$$
\frac{d^{4} y(x)}{d x^{4}}-\frac{\bar{m} \omega_{i}^{2}}{E J} y(x)=0 ; \frac{d^{2} \Phi(t)}{d t^{2}}+\omega^{2} \Phi(t)=0 .
$$

The solution of the first equation (2) will be

$$
y_{i}(x)=A \operatorname{sh} \lambda_{i} x+B \operatorname{ch} \lambda_{i} x+C \cos \lambda_{i} x+D \sin \lambda_{i} x
$$


where $A, B, C, D$ are arbitrary constants, which are defined by boundary conditions on beam's supports; $\lambda_{i}=\sqrt[4]{\frac{\bar{m} \omega_{i}^{2}}{E J}}$ - characteristic number; $\omega_{\mathrm{i}}$ is circular natural vibration frequency of a beam for $i$-th vibration mode.

To determine the vibration mode we will assess $A, B, C, D$ through initial boundary conditions $\mathrm{y}_{0}, \varphi_{0}, \mathrm{M}_{0}, \mathrm{Q}_{0}$, with $\mathrm{x}=0$.

For this purpose, we differentiate the expression (3) to the third order and obtain the following.

$$
\left.\begin{array}{l}
y_{x}=y_{0} S_{x}+\frac{\mathrm{y}_{0}^{\prime}}{\lambda} \mathrm{T}_{\mathrm{x}}+\frac{\mathrm{y}_{0}^{\prime \prime}}{\lambda^{2}} U_{x}+\frac{y_{0}^{\prime \prime \prime}}{\lambda^{3}} V_{x} \\
y_{x}^{\prime}=y_{0} \lambda V_{x}+y_{0}^{\prime} S_{x}+\frac{y_{0}^{\prime \prime}}{\lambda} T_{x}+\frac{y_{0}^{\prime \prime \prime}}{\lambda^{2}} U_{x} \\
y_{x}^{\prime \prime}=y_{0} \lambda^{2} U_{x}+y_{0}^{\prime} \lambda V_{x}+y_{0}^{\prime \prime} S_{x}+\frac{y_{0}^{\prime \prime \prime}}{\lambda} T_{x} \\
y_{x}^{\prime \prime \prime}=y_{0} \lambda^{3} T_{x}+y_{0}^{\prime} \lambda^{2} U_{x}+y_{0}^{\prime \prime} \lambda V_{x}+y_{0}^{\prime \prime \prime} S_{x}
\end{array}\right\}
$$

$S_{x}, T_{x}, U_{x}, V_{x}$ in the expressions (4) represent the Krylov's functions [9-13].

$$
\begin{array}{ll}
S_{x}=\frac{\operatorname{ch} \lambda x+\cos \lambda x}{2}, & T_{x}=\frac{\operatorname{sh} \lambda x+\sin \lambda x}{2}, \\
U_{x}=\frac{\operatorname{ch} \lambda x^{2}-\cos \lambda x}{2}, & V_{x}=\frac{\operatorname{sh} \lambda x-\sin \lambda x}{2} .
\end{array}
$$

It is known that $y_{x}^{\prime \prime}=-\frac{M_{x}}{E J} ; y_{x}^{\prime \prime \prime}=-\frac{Q_{x}}{E J}$. By placing these dependencies into expression (4), we have

$$
\left.\begin{array}{l}
y_{x}=y_{0} S_{x}+\frac{\phi_{0}}{\lambda} T_{x}-\frac{M_{0}}{\lambda^{2} E J} U_{x}-\frac{Q_{0}}{\lambda^{3} E J} V_{x} \\
\phi_{x}=y_{0} \lambda V_{x}+\phi_{0} S_{x}-\frac{M_{0}}{\lambda E J} T_{x}-\frac{Q_{0}}{\lambda^{2} E J} U_{x} \\
M_{x}=-y_{0} \lambda^{2} E J U_{x}-\phi_{0} \lambda E J V_{x}+M_{0} S_{x}+\frac{Q_{0}}{\lambda} T_{x} \\
Q_{x}=-y_{0} \lambda^{3} E J T_{x}-\phi_{0} \lambda^{2} E J U_{x}+M_{0} \lambda V_{x}+Q_{0} S_{x}
\end{array}\right\}
$$

The expression (5) defines deflection, rotation angle, torque, and transverse force, respectively, within beam's natural vibration. Using this expression, we determine the natural vibration modes of the beam installed on the elastic pillars.

We apply the following boundary condition $\boldsymbol{Q}_{\mathbf{0}}=\boldsymbol{c}_{\mathbf{0}} \cdot \boldsymbol{y}_{\mathbf{0}}$ and $\boldsymbol{M}_{\mathbf{0}}=\mathbf{0}$, where $\boldsymbol{c}_{\mathbf{0}}$ is stiffness of the elastic support; $\boldsymbol{y}_{\mathbf{0}}, \boldsymbol{Q}_{\mathbf{0}}$ и $\boldsymbol{M}_{\mathbf{0}}$ are deflection, shear force and torque, respectively, at the origin of the coordinates.

We consider the first equation of expression (5) as followed [9-13]

$$
y_{x}=y_{0}\left(S_{x}+\frac{\phi_{0}}{\lambda y_{0}} T_{x}-\frac{C_{0}}{\lambda^{3} E J} V_{x}\right)
$$

By applying boundary conditions for beam with elastic supports from third and fourth equations (5) we obtain the following, provided that $\boldsymbol{M}_{l}=\mathbf{0}$ and $\boldsymbol{Q}_{l}=-\boldsymbol{c}_{\mathbf{0}} \cdot \boldsymbol{y}_{\boldsymbol{l}}$. 


$$
\begin{aligned}
& -E J y_{0} \lambda^{2} U_{\alpha}-E J \phi_{0} \lambda V_{\alpha}+\frac{y_{0} C_{0}}{\lambda} T_{\alpha}=0, \\
& -E J y_{0} \lambda^{3} T_{\alpha}-E J \phi_{0} \lambda^{2} U_{\alpha}+y_{0} C_{0} S_{\alpha}=-y_{l} \cdot C_{0} .
\end{aligned}
$$

Solving these equations in terms of $\frac{\phi_{0}}{\lambda y_{0}}$ and $\frac{C_{0}}{\lambda^{3} E J}$, and placing obtained values and values of functions $S_{x}, T_{x}, V_{x}, S_{\alpha}, T_{\alpha}, V_{\alpha}, U_{\alpha}$ into expression (6) and after some conversion of expression, we obtain

$$
y_{x}=A\left[a_{1 i}\left(\operatorname{ch} \frac{\alpha_{i} x}{l}+\cos \frac{\alpha_{i} x}{l}\right)+a_{2 i}\left(\operatorname{sh} \frac{\alpha_{i} x}{l}+\sin \frac{\alpha_{i} x}{l}\right)+a_{3 i}\left(\operatorname{sh} \frac{\alpha_{i} x}{l}-\sin \frac{\alpha_{i} x}{l}\right)\right],
$$

where $A=\frac{y_{0}}{4\left[U_{\alpha} \cdot T_{\alpha}-\left(S_{\alpha}+1\right) \cdot V_{\alpha}\right]}$ is constant value;

$$
\begin{aligned}
& a_{1 i}=\operatorname{ch} \alpha_{i} \cdot \sin \alpha_{i}+\sin \alpha_{i}-\operatorname{sh} \alpha_{i}-\cos \alpha_{i} \cdot \operatorname{sh} \alpha_{i} \\
& a_{2 i}=\operatorname{ch} \alpha_{i}-\cos \alpha_{i}-\operatorname{sh} \alpha_{i} \cdot \sin \alpha_{i} \\
& a_{3 i}=\operatorname{ch} \alpha_{i} \cdot \cos \alpha_{i}-1
\end{aligned}
$$

The normal vibration modes will be

$$
y(x)=a_{1 i}\left(\operatorname{ch} \frac{\alpha_{i} x}{l}+\cos \frac{\alpha_{i} x}{l}\right)+a_{2 i}\left(\operatorname{sh} \frac{\alpha_{i} x}{l}+\sin \frac{\alpha_{i} x}{l}\right)+a_{3 i}\left(\operatorname{sh} \frac{\alpha_{i} x}{l}-\sin \frac{\alpha_{i} x}{l}\right)
$$

Similarly, we can obtain the normal vibration modes for a beam with one rigid pillar and one elastic pillar.

The vibration modes will be

$$
y(x)=a_{1 i}\left(\operatorname{sh} \frac{\alpha_{i} x}{l}+\sin \frac{\alpha_{i} x}{l}\right)+a_{2 i}\left(\sin \frac{\alpha_{i} x}{l}-\operatorname{sh} \frac{\alpha_{i} x}{l}\right),
$$

where $a_{1 i}=\operatorname{sh} \alpha_{i}+\sin \alpha_{i}, a_{2 i}=\operatorname{sh} \alpha_{i}-\sin \alpha_{i}$.

Table 1 illustrates formulas for determining the eigenforms of beams with various fixings, and Fig. 2 illustrates beams with different kinds of fixing at the ends. 
Table 1. Normal vibration modes for beams with different installation methods

\begin{tabular}{|c|c|c|}
\hline No. & Design & $y_{i}(x)$ \\
\hline 1 & $\frac{\bar{m}}{t}+\frac{1}{t}+x$ & $\begin{array}{l}\left(\operatorname{ch} \alpha_{i}-\cos \alpha_{i}\right)\left(\operatorname{sh} \alpha_{i} \frac{x}{l}+\sin \alpha_{i} \frac{x}{l}\right) \\
-\left(\operatorname{sh} \alpha_{i}-\sin \alpha_{i}\right)\left(\operatorname{ch} \alpha_{i} \frac{x}{l}+\cos \alpha_{i} \frac{x}{l}\right)\end{array}$ \\
\hline 2 & 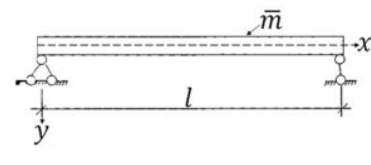 & $\sin \alpha_{i} \frac{x}{l} ; \quad \alpha_{i}=\pi i$ \\
\hline 3 & 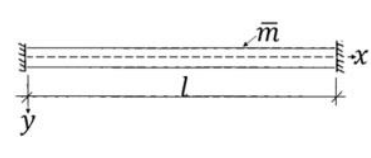 & $\begin{array}{l}\left(\operatorname{sh} \alpha_{i}-\sin \alpha_{i}\right)\left(\operatorname{ch} \alpha_{i} \frac{x}{l}-\cos \alpha_{i} \frac{x}{l}\right)- \\
-\left(\operatorname{ch} \alpha_{i}-\cos \alpha_{i}\right)\left(\operatorname{sh} \alpha_{i} \frac{x}{l}-\sin \alpha_{i} \frac{x}{l}\right)\end{array}$ \\
\hline 4 & 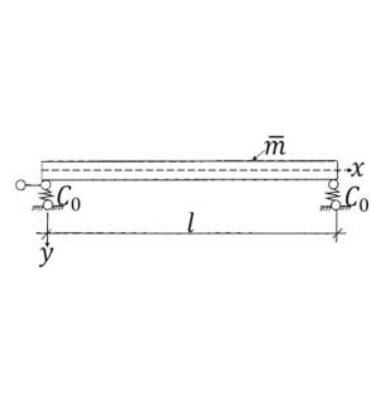 & $\begin{array}{l}a_{1 i}\left(\operatorname{sh} \frac{\alpha_{i} x}{l}+\sin \frac{\alpha_{i} x}{l}\right)+ \\
+a_{2 i}\left(\sin \frac{\alpha_{i} x}{l}+\operatorname{sh} \frac{\alpha_{i} x}{l}\right)+ \\
+a_{3 i}\left(\sin \frac{\alpha_{i} x}{l}-\operatorname{sh} \frac{\alpha_{i} x}{l}\right) \\
a_{1 i}=\operatorname{ch} \alpha_{i} \cdot \sin \alpha_{i}+\sin \alpha_{i}-\operatorname{sh} \alpha_{i}- \\
-\cos \alpha_{i} \cdot \operatorname{sh} \alpha_{i}, \\
a_{2 i}=\operatorname{ch} \alpha_{i}-\cos \alpha_{i}-\operatorname{sh} \alpha_{i} \cdot \sin \alpha_{i}, \\
a_{3 i}=\operatorname{ch} \alpha_{i} \cdot \cos \alpha_{i}-1\end{array}$ \\
\hline
\end{tabular}

From expression (8) we can get the normal vibration modes for a beam with rigid pillars where $C_{0} \rightarrow \infty$ and for a beam with no pillars where $C_{0}=0$ (See Fig. 2).

For the first case, when $\mathrm{C}_{0} \rightarrow \infty \alpha=\pi i$ and $\sin \pi i=0$, we get $y(x)=\sin \frac{\pi \cdot i \cdot x}{l}$, from expressions (8) and (9), which matches with normal vibration modes of a beam installed on rigid pillars (see table 1 , position 2 , and fig. $2 \mathrm{a}$ ). For the second case, when $\mathrm{C}_{0}=0$, then $\operatorname{ch} \alpha_{i} \cdot \cos \alpha_{i}-1=0$, and after certain conversions the expression (8) will be as following

$$
y(x)=\left(\operatorname{ch} \alpha_{i}-\cos \alpha_{i}\right)\left(\operatorname{sh} \frac{\alpha_{i} x}{l}+\sin \frac{\alpha_{i} x}{l}\right)-\left(\operatorname{sh} \alpha_{i}-\sin \alpha_{i}\right)\left(\operatorname{ch} \frac{\alpha_{i} x}{l}+\cos \frac{\alpha_{i} x}{l}\right),
$$


which matches with formula for determining the natural vibration modes of a beam with no pillars (see table 1, position 1, and fig. $2 \mathrm{c}$ ).

(a)

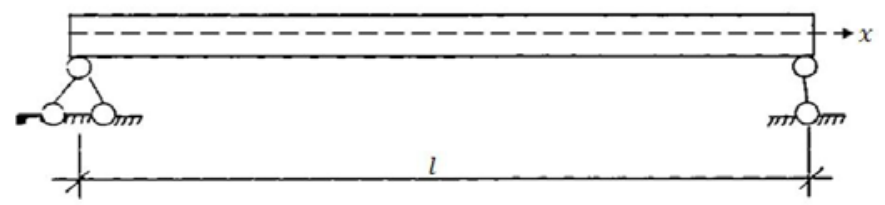

(b)

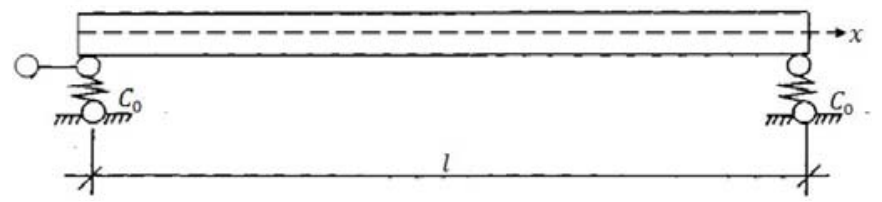

(c)

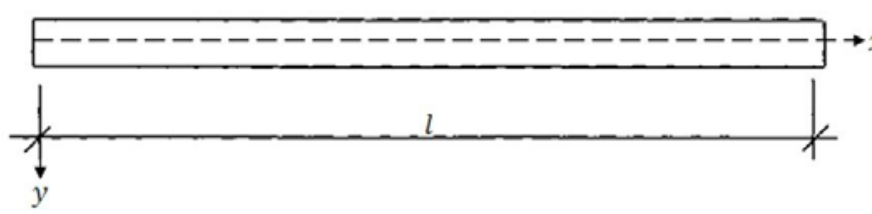

Fig. 2. Design of beams with different pillars at the ends: (a) beam with swinging pillars;(b) beam with elastic pillars;(c) beam with no pillars (hanging)

The normal vibration modes for beams with different installation methods are illustrated in the fig. 3 .

The obtained formulas for determining the natural vibration modes are used in calculating the span of a bridge with seismically insulating elastic supports for the effects of seismic and moving loads $[14,15]$.

The table 1 specifies the natural vibration modes for beams with different pillars at the ends. The positions 1, 2, 3 in the table are taken from the previous works $[2,9,10,11]$, and position 4 is proposed by the authors. Positions 1,2 arise from position 4 , when $C_{0}=0$, $\mathrm{C}_{0}=\infty$, respectively.

(a)

(b)

(c)
First mode

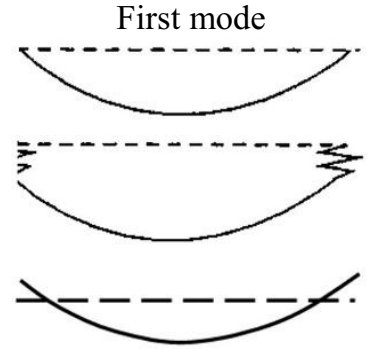

Second mode

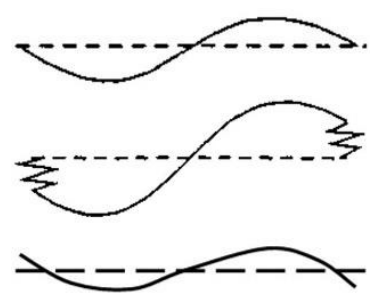

Fig. 3. Normal vibration modes for beams with different installation methods: (a) beam with rigid pillars;(b) beam with elastic pillars;(c) beam with no pillars

The proposed formulas (8) and (9) can be used for horizontal transverse vibration of beams. Then in the formulas take $z_{x}$ instead of $y_{x}$.

In $[16,17]$, using the same boundary conditions, formulas were proposed to determine the frequencies of natural vibrations of beams on elastic support parts. 


\section{Conclusions}

The proposed formulas (8), (9) can be used to calculate the bridge spans for seismic and moving loads, and formula (8) is used to calculate intermediate spans, and formula (9) is used for side spans.

Formula (8) can be used to determine the eigenmodes of the transverse vibration of the superstructure with seismic-insulating sliding bearing parts, replacing the sliding friction force of the bearing parts with the reduced stiffness of the elastic bearing parts from the condition that the work of the friction and elastic forces is equal.

$$
F_{\mathrm{Tp}} \cdot \Delta=\frac{C_{0} \cdot \Delta^{2}}{2} ; \text { which gives } C_{0}=\frac{2 F_{\mathrm{Tp}}}{\Delta}
$$

here $\Delta$ is the maximum horizontal sliding of the support parts. It is set depending on the seismic scale of the construction site [4].

\section{References}

1. GOST 32020-2012. Rubber bearing parts for bridge construction. Technical terms.

2. B. G. Korneev, I. M. Rabinovich (Eds.), Handbook for structural dynamics. //Справочник по динамике сооружений., Publishing House for Construction Literature, Moscow, 1972, p. 512

3. M. Ch. Apsemetov, M. Murzakhmatov, Reducing the dynamic impact of moving loads on small-span highway bridge. //Снижение динамического воздействия подвижной нагрузки на автодорожные мосты малых пролетов., in: Earthquake-proof construction in Kyrgyzstan. //Сейсмостойкие конструкции зданий и сооружений в Киргизии., Frunze, 1990, pp. 77-80.

4. M. Ch. Apsemetov, Practical calculation of rigid structures with seismic insulating sliding belt for seismic impact. //Практический расчет сооружений жесткого типа c сейсмоизолирующим скользящим поясом на сейсмические воздействия. EARTHQUAKE ENGINEERING. CONSTRUCTIONS SAFETY //СЕЙСМОСТОЙКОЕ СТРОИТЕЛЬСТВО. БЕЗОПАСНОСТЬ СООРУЖЕНИЙ, No. 5, Moscow, 2017, pp. 20-24.

5. T. Zh. Zhunusov, M. Ch. Apsemetov, Seismic isolation units in bridge design. //Сейсмоизолирующие узлы в конструкциях мостов. Bulletin of KSUCTA No. 1 (2002) $49-54$, Bishkek.

6. T. Zh. Zhunusov, M. Ch. Apsemetov, Girder road bridges on elastic bearing parts. //Балочные автодорожные мосты на упругих опорных частях. International conference proceedings, Bishkek, June 14-17, 1994, pp. 175-176.

7. G. N. Kartsivadze, Seismic resistance of artificial road structures. //Сейсмостойкость дорожных искусственных сооружений. Publishing house «Transport», Moscow, 1974, p. 263.

8. I. M. Rabinovich, A. P. Sinitsyn, O. V. Luzhin, V. M. Teterin, Designing of constructions for impulsive impacts. //Расчет сооружений на импульсивные воздействия, Publishing House for Construction Literature, Moscow, 1970.

9. V. V. Bolotin, The problem of bridge vibrations under the impact of a moving load. //Задача о колебаниях мостов под действием подвижной нагрузки, USSR Academy 
of Sciences. Department of technical sciences. Mechanics and Mechanical Engineering (4) (1961) 109-115.

10. V. A. Kiselev, Structural Mechanics: Special course. Structural dynamics and stability. //Строительная механика: Специальный курс. Динамика и устойчивость сооружений, Publishing House for Construction Literature, Moscow, 1980.

11. S. P. Timoshenko, D. H. Young, W. Weaver, Vibration problems in Engineering. //Колебания в инженерном деле, FIZMATLIT, Moscow, 1985, pp. 205.

12. Y. G. Panovko, Introduction to the theory of mechanical vibrations. //Введение в теорию механических колебаний. Publishing House «Nauka», Moscow, 1971, p 240.

13. A. N. Krylov, Collection of works of Academician A.N. Krylov. T. 10. Vibration of ships. //Собрание трудов академика А. Н. Крылова. Т. 10. Вибрация судов, USSR Academy of Sciences, Moscow-Leningrad, 1948, pp. 108-119.

14. M. Ch. Apsemetov, T. K. Muktarov, A. Dzh. Iskakova, Application of differential equations in solving the problems of the dynamics of structures. //Применение дифференциальных уравнений при решении задач динамики сооружений., Bulletin of KSUCTA No. 4 (50) (2015) 22 - 30, Bishkek.

15. M. Ch. Apsemetov, Solving the differential equation of the forced transverse vibration of the beam on elastic supports. //Решение дифференциального уравнения вынужденного поперечного колебания балки на упругих опорах, Bulletin of KRSU Tome 16, No 9 (2016) 81 - 84, Bishkek.

16. M. Ch. Apsemetov (2017), Some questions about own vibrations of structures in seismic insulation of constructions. //Некоторые вопросы о собственных колебаниях конструкций при сейсмоизоляции сооружений. Earthquake engineering. Constructions safety. No 6, Moscow, pp. $44-49$.

17. M. Ch. Apsemetov, K. K. Alykulov, T. K. Muktarov (2017), Determination of the natural vibration frequency of a beam on elastic supports. //Определение частоты собственных колебаний балки на упругих опорах. Natural and technical sciences. No 11 (113), Moscow, pp. $213-218$. 